\title{
Putting a price on drugs: An economic sociological study of price formation in illegal drug markets
}

\author{
Postprint version
}

Reference: Møller, Kim and Sveinung Sandberg (2019): Putting a Price on Drugs: An economic sociological study of price formations in illicit drug markets. Criminology. Published online. doi.org/10.1111/1745-9125.12202

\begin{abstract}
Prices in illegal drug markets are difficult to predict. Based on qualitative interviews with 68 incarcerated drug dealers in Norway, we explore dealers' perspectives on fair prices and the processes that influence their pricing decisions. Synthesized through economic sociology, we draw on perspectives from traditions as different as behavioral economics and cultural analysis to demonstrate how participants in illicit drug distribution base their pricing decisions on institutional context, social networks, and drug market cultures. We find that dealers take institutional constraints into consideration and search for niches with high earnings and low risks. The use of transactions embedded in social networks promotes a trusting form of governance, which enables strategic network management and expedient distribution but also uncompetitive pricing. Finally, dealers' pricing decisions are embedded in three different cultures narratives: business, friendship, and street cultural stories, with widely varying implications for prices. Our findings demonstrate how an economic sociology of illicit drug distribution can extend insights from behavioral economics and cultural studies into a coherent criminology of illegal drug markets.
\end{abstract}




\section{INTRODUCTION}

Price is arguably the most central concept in economics where it represents the aggregate result of individual choices. Conventional economic theory assumes economic agents always choose the lowest price. This implies demand of any good declines as the price increases. Using this price theory, economists have modeled many aspects of human behavior, including crime and drug use (Becker, 1968; Bushway and Reuter, 2008). Classical sociologists, however, understand pricing as another category of social action (Swedberg, 2003). For instance, Weber (1978 [1922]: 108) viewed price as a result of struggle between competing interests and power groups. Durkheim (1933 [1893]: 206-19) observed prices as an expression of social norms, what society deems just and therefore outside the influence of individual choice. Considering these early works, contemporary sociologists took to the idea that prices can only be understood with reference to the social structures that surround them (Beckert, 2011; Granovetter and Swedberg, 1992).

Illicit drugs are expensive because criminalization "taxes" all aspects of distribution (Reuter and Kleiman, 1986). Offenders require compensation for their risk of arrest and bodily harm. As a result, cannabis is worth its weight in gold and cocaine and heroin are even costlier. While this restricts consumption, it also causes problems as dealers amass illegal earnings and addicted users struggle to finance their use (Becker, Murphy, and Grossman, 2006; Gallet, 2014). Further, illicit drug prices vary more than prices for other products - a variation that exceeds what economic analysis anticipates (Caulkins and Reuter, 2006), and this complicates policy formulation (Manski, Pepper, and Petrie, 2001: 116). Caulkins and Reuter (1996: 1264) concluded that the "magnitude of that variation, particularly over time and place, offers prospects for gaining substantial insight into behavior. It is not only better price data, but also better analyses that are needed." We answer this call by exploring the links between prices and the social structures that surround economic exchange. 
Illicit drugs are not sold in competitive markets that are organized by the laws of supply and demand with agents who have perfect information. There are no state institutions that regulate quality standards, ensure fair competition, and enforce contracts; hence, participants must develop informal ways of building trust and reducing uncertainty. Drugs are therefore distributed in social networks of known partners that offer protection against law enforcement intervention (Benson and Decker, 2010; Morselli, 2009). Prices are also influenced by cultures that "set shared standards on how to calculate the 'right' price" (Beckert 2011: 772). Different types of drugs fluctuate in popularity over time and their use and distribution are associated with norms that set expectations for pricing behavior (Golub, Johnson, and Dunlap, 2005). The social context surrounding illicit drug transactions is therefore pivotal to understand pricing mechanisms.

This article demonstrates how perspectives from economic sociology relate to behavioral economic contributions to criminology and cultural studies of illegal drug markets. Our aim is not only to contribute to interdisciplinary thinking on illicit drug prices, but also to demonstrate how economic sociology can synthesize these approaches. Using 68 qualitative interviews with imprisoned drug dealers in Norway, we examine price formation from three economic sociological perspectives focusing respectively on formal legal institutions, social networks, and culture (Aspers, 2011; Fligstein and Dauter, 2007). We argue that economic sociology can encompass diverging disciplinary contributions such as behavioral economics and narrative analysis into a coherent theoretical framework. This criminology of illegal drug markets is more realistic than neoclassic economic research and easier to generalize than cultural studies.

\section{THE ECONOMIC SOCIOLOGICAL APPROACH TO PRICING: INSTITUTIONS,} NETWORKS, AND CULTURE

The institutional tradition of economic sociology examines how prices emerge from formal statedevised rules that regulate and constrain economic actors (Streeck and Thelen, 2005). The "law is 
constitutive for most economic phenomena" (Swedberg, 2003: 129) because the state requires that producers use contracts, conform to quality standards, and pay debts. In contrast, drug dealers work in direct opposition to the state and the authorities actively prevent binding agreements and information flows (Beckert and Wehinger, 2013; Caulkins and Reuter, 2010).

Economic research that has modeled law enforcement effects on illicit drug prices suggests sellers add a risk premium so their expected utility gains from selling drugs exceed the utility gains they would receive from other activities (Becker, 1968; Reuter and Kleiman, 1986). However, beyond basic levels, policing is an inefficient way of increasing drug prices (Becker, Murphy, and Grossman, 2006). According to economists, dealers' central problem is their lack of reliable information. As dealers cannot accurately anticipate their risks of arrest or fraud, uncertainty about future costs complicates pricing (Akerlof, 1980; Simon, 1979; Titman, 1985). Areas of inquiry for the institutional perspective in economic sociology concern the specificities of formal regulation and policing. To persist in the illegal drug business, dealers must continuously adapt and strategically maneuver in a high-risk environment while also focusing on managing a profitable business.

The network tradition of economic sociology builds on Granovetter's (1985) argument that economic transactions are embedded in networks of ongoing relations (Krippner, 2002). This perspective emphasizes how repeated transactions with known partners in trust-based, nonhierarchical, loose organizations affect economic outcomes (Thompson, 2003). Though actors in networks consider economic efficiency and profits when pricing products, they also include longterm goals and their partners' ability to earn money (Uzzi, 1999; Williamson 1981). Therefore, network prices deviate from the competitive equilibrium price of neoclassic economics. Research on networks in the legal economy has examined power (Beckert, 2011), status (Podolny, 2005), and trust (Nooteboom, 1996) as price-influencing mechanisms. 
Sellers in networks are incentivized to provide fair prices so buyers do not change suppliers (Kahnemann, Knetsch and Thaler, 1986; Klemperer, 1987). However, fair pricing is not straightforward owing to uncertainty regarding the drugs' purity. In one way, illicit drug prices reflect the product standard, i.e. purity (Caulkins, 2007). However, as this standard is difficult to determine and easy to manipulate, the seller's status influences prices (Akerlof 1980; Reuter 1983). In practice, standard and status intermingle. In the legal economy, as illustrated by the pricing of art and wine, perceived quality (Podolny, 2005) and symbolic value (Uzzi and Lancaster, 2004) can influence prices more than actual differences between products (Aspers, 2011; Velthuis, 2005). In the illegal context, pricing is a matter of trust and one key contribution of economic sociology is to extend the analysis of economic phenomena with notions of trust (for overviews of the concept see Swedberg, 2003: 248-9; Williamson, 1993). Participants in criminal networks learn to trust each other through informal methods. They demonstrate reliability by respecting verbal agreements and reciprocating trusting behavior (Moeller and Sandberg, 2015).

Finally, the cultural approach in economic sociology examines how the institutional context is interpreted and how culture influences interpersonal trust. Drawing on Smith (1989) and Zuckerman (1999), Aspers (2011) distinguished between general and particular market cultures where the general market culture refers to economic regularities such as supply and demand, competition, efficiency, and profits. Adler (1993) noted that drug dealers compared their actions to legitimate business practices (see also Dwyer and Moore, 2010) and these economic regularities may exist partly because they are continuously "performed" and acted out (MacKenzie, Muniesa and Siu, 2007). Conversely, a particular market culture can deviate from these regularities and specify community standards for pricing or reference the norms of a violent street culture (Anderson, 1999) or subcultures associated with specific drugs (Golub, Johnson and Dunlap, 2005). There is a long tradition of studying subcultures (Young 1971) and drug dealers (Bourgois 1996; 
Jacobs, 2000) in criminology and sociology. Drawing upon Bourdieu's (1984) economic cultural sociology and Thornton's (1995) concept of subcultural capital, the concept 'street capital' has been used to describe that which ties together street cultures and the economy of drug distribution (Sandberg, 2008).

The cultural approach in economic sociology is closely linked to studies of narratives, as cultures are created and upheld by narratives (Presser and Sandberg, 2015). Shiller (2017) proposed narrative economics to study how popular stories influence economic fluctuations. He noted that narratives "have the ability to produce social norms that partially govern our activities, including our economic actions" (Shiller 2017: 976; see also Morson and Schapiro, 2017). Pricing decisions are embedded in cultural narratives that vary across social, historical, and geographical settings. General market culture involves the narrative of the protagonist who conducts drug business in a calculated, controlled, and competent manner to maximize income (Sandberg and Fleetwood, 2017). However, in other social networks, this narrative may be challenged by cultural stories that emphasize fair prices between friends (Coomber, Moyle and South, 2016). Price formation in drug distribution is embedded in social networks. These networks emphasize friendship and fair prices, but are also responsive to the surrounding general market culture and more particular drug subcultures.

\section{AN INTERDISCIPLINARY APPROACH TO PRICES}

To grasp the complexity of illicit drug pricing, we propose an interdisciplinary approach synthesized in economic sociology. Behavioral economists were critical of neoclassic economic theory's assumptions and predictions. They attempted to analyze decision-making realistically by drawing on other social sciences and added assumptions of bounded rationality, search costs, and satisficing (Pogarsky, Roche and Pickett, 2018). Bounded rationality means actors have limited information, time, and cognitive capacities. Decision-making is not a purely cognitive process, and 
actors do not maximize utility but aim for outcomes they consider satisfactory (Simon, 1979). Finally, there are search costs when switching to alternative sellers (Diamond, 1971; Klemperer, 1987) and organizational structures therefore influence pricing (Williamson, 1981).

These assumptions bring economics closer to a sociological understanding of economic processes, but arguably, social context is still under-appreciated in behavioral economics (see also Granovetter 1985). We believe that economic research on drug markets can benefit from detailed cultural knowledge derived from sociological and criminological traditions, and vice versa. Economics has received only scant attention in criminology. While economists try to grasp general market mechanisms, criminologists have focused on individual marketplaces (Bushway and Reuter, 2008; Moeller, 2018). Studying economic processes through the economic sociological perspectives of institutions, networks, and culture, provide a systematic way to connect macro and micro levels of analysis (Fligstein and Dauter, 2007). We argue that such a theoretical integration will improve our understanding of illicit drug prices and co-offending behavior. This study is specifically aimed at exploring how social context influences pricing decisions in illegal drug markets. In these efforts however, we also hope to demonstrate promises of economic sociology for criminology more generally.

\section{METHOD}

This study is based on interviews with 68 incarcerated drug dealers in six Norwegian prisons. The sample was recruited by approaching prison officials, holding general meetings in prisons, and snowballing within the prisons (interviewees suggested other interviewees). The inclusion criterion was experience with drug dealing or drug trafficking. Though most of the interviewees were serving drug-related sentences, some were convicted of violent crimes. In Norway, drug felons are often drug mules that may have never been to the country before their arrest. Hence, we selected 
interviewees that spoke fluent Norwegian because we were interested in data on Norwegian drug markets and not smuggling per se. The interviewees were white, economically and socially at the margins of society, and identified with street culture (Sandberg and Fleetwood, 2017). Many had extensive histories of drug use. While cannabis and amphetamines were the main drugs distributed (see Table 1), most had sold several different types of drugs. The mean age was 35 with a range from 20 to 50 years.

- Table 1 about here -

All interviewees were experienced with drug distribution. It varied from lower-level sales to large-scale international trafficking, but most had mid-level experience. While Norway has organized criminal groups, none of our participants were associated with these. Most were part of loosely organized and ad hoc structures often found in drug distribution (Desroches, 2007; Morselli, 2009). We provide information about the level of dealing for drug dealers quoted in the analysis (lower, mid-, and high level). For simplicity, and as it can be difficult to categorize involvement in drug distribution (Pearson and Hobbs, 2003), we follow guidelines from the Norwegian Director General of Public Prosecution, which demarcates three levels of severity in the penal code (see Table 2). Though we do not use this categorization analytically, we mention it together with information about sex and the drugs dealers sold in the findings, to give quotes some context.

- Table 2 about here -

One common criticism of research on imprisoned populations is that this is a selective group of unsuccessful actors and is, thus, not representative of all offenders (Wright and Decker, 
1994). However, prison interviews have advantages. They allow access to a hidden population and participants are likely to be motivated, contemplative, and clear-headed (Copes et al., 2015). Further, many individuals from drug-dealing populations are eventually imprisoned (Decker and Chapman, 2008).

The interviews were conducted from 2010 to 2013 and were 1.5 to 2.5 hours each in length. They were conducted in Norwegian by a team of five researchers with experience interviewing hard-to-reach populations. The interviews were recorded, transcribed, and coded in the qualitative data processing program Hyper Research and a professional translator translated the quotes into English. We followed a general interview guide developed in advance, but interviewers could follow up on themes that emerged during the interviews.

For the analysis, we coded several key themes broadly. The codes followed our predefined research interest in drug dealing but had many subcategories, including price, credit, conflict resolution, and organization of work. The price code included all mentions of prices for different drugs and was the starting point for the analysis. We coded these price data further and more analytically and identified themes that could be linked to different traditions in economic sociology: risk- and cost-reducing strategies, different categories of transaction partners reflecting the network perspective, and cultural narratives influencing pricing decisions. This is a common coding method for qualitative studies where ideas emerging from empirical data are combined with theoretical concepts (Kvale and Brinkmann, 2008). Both authors coded the themes to improve interrater reliability.

Interview data are well-suited for analyzing the content and dynamics of ties in social networks and understanding cultures. However, they are arguably not as appropriate for analyzing institutional contexts. A more thorough institutional analysis of price formation would have included a broader spectrum of data sources, such as legal and policy documents and interviews 
with law enforcement agents. Instead, the institutional section of our analysis emphasizes how dealers navigate in the illegal context and does not focus on the details of this context. Overall, we note that our study is explorative and not a comprehensive examination of institutions, networks, and cultural approaches in economic sociology. With an emphasis on price formation, we provide examples of analyses that can be performed within these three approaches. We hope this will inspire other researchers to expand the economic sociological perspective further in criminology.

\section{FINDINGS}

The findings are organized into three sections based on the economic sociological traditions identified in the review: institutions, networks, and culture. We focus on drug dealers' descriptions of pricing practices, and emphasize how these approaches contribute to analyzing different aspects of illicit drug transactions in Norway.

\section{THE INSTITUTIONAL APPROACH TO PRICES}

Economic sociology describes five ways in which institutions affect market prices in the legal economy. These are formal rules for pricing, regulation of the externalization of costs, reducing market uncertainty, taxation and accounting requirements, and the price for money (Beckert, 2011). In drug distribution, it is criminalization and the associated lack of state regulation that exert most influence on prices. Criminalization inadvertently facilitates, motivates, and shapes incentives for all participants (Becker, 1968; Reuter and Kleiman, 1986). With no official product standards and contracts, criminalization leads to local negotiation of prices. Crucially, participants' lack of reliable information on the legal risks they face adds uncertainty to all aspects of the distribution process. As dealers cannot accurately anticipate future costs, this complicates pricing (Titman, 1985). In the 
following section, we describe how criminalization introduces a risk premium, increases uncertainty, and adds inventory costs.

\section{Risk premiums and market niches}

The criminalization of certain psychoactive drugs imposes great costs on distributors.

Consequently, drug prices are extremely high. Compared to other countries, Scandinavian welfare states have lenient criminal justice systems; however, Norwegian drug laws are an exception. The maximum penalty for drug trafficking and homicide is 21 years. Combined with Norway's geographical location, far from drug-producing countries, the potential earnings and costs associated with dealing are very high. Hence, simple commodities become highly valuable — some more than others.

A male mid-level cannabis dealer (36) explained the basic risk premium: "You have to weigh it against the risk, right? Prison time, what happens if you get caught, right? Okay, then maybe you raise the price by a few thousand kroner ${ }^{1}$." The dealers explained how they sought market niches they perceived to have high earnings and low legal risk. A male high-level GHB ${ }^{2}$ dealer (44) stated his choice of substance with the following reasoning:

You combine the right amount of caustic soda and water at the right temperature. Cooking that is an art. But a liter [GBL] then becomes three liters [GHB]. I give 20,000 ( US\$

\footnotetext{
${ }^{1}$ All monetary values provided in Norwegian kroners (NOK) with a rounded US\$ value in brackets. At the time of data collection NOK $100=$ approximately US $\$ 12$ and US\$10 = approximately NOK 83.

2 GHB (Gamma hydroxybutyrate) is an anesthetic with sedating properties, and GBL (Gamma Butyrolactone) are chemicals closely related to GHB (https://www.drugwise.org.uk/ghb/). GHB is sometimes sold under the name liquid ecstasy, but it is not related in terms of effects. It has been known as a "date rape drug" due to the sedative effects (https://www.drugs.com/illicit/ghb.html).
} 
2,400) for 100 liters GBL, which will be 300 liters GHB that I sell wholesale for 3,000 kroner ( US\$ 360) a liter. In other words, I make 950,000 kroner ( US\$ 114,000) in profit for every 100 liters $^{3}$. Do you realize how ridiculous that is? That's more net profit than on heroin. 30,000 ( US\$ 3,600) and I paid for gas and goods and the trip and had a hell of a party in Germany. And I ended up making over a million.

The paradox that criminalization also presents opportunities was reflected in all dealers' descriptions of their activities. The variation in risks and potential earnings is a function of the criminal sanctions delineated by drug types and amounts (see Table 2). These sanctions are uniform across the country; however, there are regional variations in law enforcement intensity. Several dealers explained how prices increase the further you travel from the Norwegian capital, Oslo. This arbitrage is well-known (e.g., Caulkins, 2007), but local planning decisions could inadvertently increase drug prices in some regions and introduce attractive criminal opportunities. A male midlevel amphetamine dealer (46), operating in a city outside of Oslo, explained how he exploited this variation for his economic benefit:

They got a rehabilitation institution there in the 70s and 80s and it attracted a lot of trash to the town. A long story: High prices and a violent environment, artificially high prices. One of the most expensive cities for buying drugs, still is. At the time, a gram of amphetamine cost a thousand kroner in a nearby city, but here, it was 1,500 kroner ( US\$ 180). So we had a branch over there. Yeah, of course we did. We paid 200 ( US\$ 24), at most 300

\footnotetext{
${ }^{3}$ Note that the dealer's calculations here are not entirely correct. With the numbers provided the profit should be NOK 880,000 . It is used as an example to make a point in everyday conversation.
} 
kroner ( US\$ 36) for the amphetamines we got from Oslo. Man, did it pay off (laughs). Everyone made money on it anyways.

Though they sought profitable combinations of drug types, amounts, and regions, the assessment of earnings and risks was not uniform between drug dealers or static over time. A male mid-level Rohypnol ${ }^{4}$ dealer (29) explained why he preferred to deal prescription pills and reflected on opportunity costs:

It requires so little work for so much money. (...) But maybe it's not worth it. It's a question of where you are in life. If you have nothing to lose, you've got nothing to lose. If you have family and stuff, kids and stuff, then you have a lot to lose. That's another thing.

The opportunity costs of engaging in illegal drug dealing change over time. Expected earnings were weighed against risks, but these assessments also included quality of life, family and other agerelated life events (Becker, 1968; Bushway and Reuter, 2008). In this sense, the risk premium is not uniform for all offenders. Rather, we may say institutional-level rules work as a flat tax on drug distribution. Accordingly, these risks give dealers an incentive to allocate tasks to those willing to perform them for low compensation. A female mid-level amphetamine dealer (45) explained the basic premise behind paying others to work for you: "You can't run all the errands yourself, and you have to get others to do things for you. Then, they have to get paid for it, and you still want to profit from it."

\footnotetext{
${ }^{4}$ Rohypnol is the brand name for an intermediate-acting benzodiazepine with properties similar to those of Valium (https://www.drugs.com/illicit/rohypnol.html).
} 
Recruiting potentially opportunistic co-offenders to perform undesirable tasks introduce a new dimension to problem of getting reliable information in illegal drug markets. In economic theory, this is a principal-agent problem, similar to the relationship between a proprietor and tenant or bank and borrower (Stiglitz and Weiss, 1981). There is adverse selection in the pool of potential partners and the most capable are not necessarily willing. Banks use various screening devices to reduce their risks when lending money. In illegal markets however, there are no audited books on prior performance (Reuter, 1983). Therefore, drug dealers have to devise informal means of assessing reliability.

\section{Uncertainty and deterrence management}

The threat of criminal sanctions was constant in the dealers' explanations of their activities, but they did not have accurate, updated information on law enforcement priorities and arrest risks. This uncertainty permeates the drug distribution process and complicates all decisions. Despite this, many interviewed dealers explained their actions with reference to risk probabilities (for a discussion of these terms see Carruthers, 2013).

A male high-level amphetamine dealer (40) stated, "There's always someone getting caught for something. That's included in the price. But if one gets caught, you can bet that there are about 25 that don't." Other dealers recognized the inherently bounded rationality of their decisions. A female mid-level amphetamine dealer (24) described this as follows: "But in a way, I didn't realize how risky it was." Making decisions in a context of uncertainty led to speculation regarding police intelligence on drug dealing. A male mid-level ecstasy dealer (29) similarly said: "I think they know a lot more than we think." Several dealers clarified how they would attempt to manage risks through intricate strategies aimed at manipulating police perceptions of their offending. A male mid-level amphetamine dealer (46) explained how he reduced police attention by creating the impression he only sold small amounts: 
Knowing that I was hot, I'd put up these smokescreens; I'd sell some grams to some bums from my house, so if they got stopped, they got caught with one gram. So, they'd make an assessment, in a way, "OK, he's selling grams, he is not interesting," while I was actually selling 100 grams each time I put up smokescreens and sold grams.

Drug dealers explained how they continuously adapted their actions in response to law enforcement. In this example, it involved surrendering others to influence police investigations to avoid criminal sanctions. Deterrence is a perceptual process. Offenders interpret their perceived sanction risk, and our data illustrate that this process has two directions because police also have imperfect perception of offenders' actions (also see Jacobs, 2000; Wright and Decker, 1994).

Institutional rules create the macro-level framework that drug dealers navigate. This involves a pervasive uncomfortable feeling, as well as bold counter-strategies. From a theoretical economic perspective, this is the problem of pricing under uncertainty, as dealers do not know their future costs from conviction and incarceration. This may help explain why increasing law enforcement pressure does not raise drug prices (Becker, Murphy, and Grossman, 2006; Caulkins and Reuter, 2010). Though dealers have a broad understanding of the legal framework and variations in local policing strategies, they do not have the required information to respond with price changes when there are incremental adjustments in this institutional environment.

\section{Inventory costs and expediency}

Beckert (2011) noted that institutional constraints increase costs by setting rules for taxation and accounting practices. Though these requirements do not apply directly to the illegal context, drug distributors have analogous costs that follow from criminalization. A central category of costs addressed by many of the interviewees was inventory. Dealers stressed the importance of selling 
their drugs quickly to avoid having large quantities and thus amassing costs and increasing uncertainty. This expediency directly influences prices. A male mid-level cannabis dealer (23) explained his considerations as follows:

I'd rather sell 50 kilos to earn half a million, right? You can't sell those 50 kilos for 30,000, 35,000 ( US\$ 3,600-4,200) for a kilo; that's the normal price for a kilo. Because you gotta sell it fast; you wouldn't want to sit on it. So then, you gotta sell for less, at a lower price. Then, you'll be earning only 10 kroner a kilo ( US\$ 1.2), and then, you have to sell a lot [to make real money]. That means bigger risks, and it'll take more time then, and then people often take a "quick risk," right?

Note that this, and other statements from dealers on costs and expediency, is embedded in an economic logic that we later refer to as "business narratives" (Sandberg and Fleetwood, 2017). Further, low-quality drugs present a special inventory cost problem. Norwegian drug laws do not distinguish sanction severity based on purity (except if drugs are unusually high purity, in which case sanctions are increased). Hence, the inventory costs of low-quality drugs are disproportionately high per weight unit. A male high-level cannabis (32) dealer said this when asked about low-quality cannabis:

Interviewer: What do you do if you're sitting on 50 kilos of schwag. How does one get rid of it?

Dealer: Get rid of it as fast as possible (laughs).

Interviewer: Does one get rid of it or just move it?

Dealer: Just get rid of it; get money. 
Several drug dealers we interviewed described inventory as a major concern. From a theoretical economic perspective, this presents another problem involving uncertainty about future costs. They must compare the costs of holding inventory while searching for a better deal, with the expected gain from possibly finding a better price (Diamond, 1971; Klemperer, 1987). Lack of information on alternative buyers' willingness to pay implies inventory costs increase. Dealers cannot expect compensation for this however, as it is not relevant to the buyer (Kahneman, Knetsch, and Thaler, 1979). The result may be that dealers accept a less-than-optimal price.

The desire for expediency decreases prices in three ways. First, dealers may accept lower prices per weight unit to offload inventory. Second, they may provide larger-than-usual quantity discounts. Thirdly, the price of low-quality drugs depreciates faster owing to the disproportionately high legal risks to potential earnings. Together, this implies the relationship between prices and inventory costs is not linear over time. This problem further elucidates how balancing risks and prices are contingent on individual and situational factors. Risk-averse dealers may prefer expediency to the potential added earnings from finding a buyer willing to pay more. However, as timing matters, dealers may sell at lower prices after holding inventory for a while. Law enforcement taxes drug distributors, but for inventory, there are interests on the interests.

In essence, the institutional approach in economic sociology can be used to study how formal regulation influences drug prices directly and indirectly. Legal risks directly influence the risk premium and the indirect influence can be seen in dealers' adapting to the uncertainty of a social context where the consequences of misjudging co-offender's are severe. The effects of institutional constraints on drug prices do not only vary with offenders' position in the drug distribution system, the type of drugs sold, and local law enforcement practices and planning decisions, but also across offenders' life-course and in relation to inventory held. Drug dealers in 
this study describe the trade-offs they face, including balancing potential earnings with risk willingness, diffusing risks by recruiting labor, and keeping inventory costs low by satisficing on price. From the behavioral economic perspective, these are essentially information problems. The institutional perspective adds to this by demonstrating how actors collect information, sometimes at a cost, to improve their decision-making, moving from uncertainty towards risk (Carruthers, 2013). This illustrates the importance of including economic sociology to studies of illegal drug markets.

\section{THE SOCIAL NETWORK APPROACH TO PRICES}

Because drugs are illegal, promotion, sales, and pricing decisions often occur in social networks. While social networks are important in the legal economy, they are indispensable in the illegal economy because of the absence of official marketplaces. Economic sociology emphasizes that pricing in networks is part of a long-term interpersonal relationship that includes strategic planning (Uzzi, 1999; Uzzi and Lancaster, 2004). Similar issues are examined in behavioral economic theories on switching costs and fairness. Switching costs occur when buyers seek new sellers and have to learn to work with them while also losing the experience and repeat-purchase discounts from their previous supplier (Diamond, 1971; Klemperer, 1987). The rules of fairness stipulate that prices should reflect community standards, previous transactions, and that increases must have legitimate causes (Kahnemann, Knetsch and Thaler, 1986). Together, this makes network prices less volatile than prices in open markets (Granovetter and Swedberg, 1992). Below, we describe how prices in networks are affected by the mechanisms of power, status, and trust.

\section{Power reduces competitive pricing}

Power in network relations influences drug prices in three ways: it allows credit provision, it provides stability, and it enables price fixing. Credit prices are higher than cash prices because of the costs involved in making and collecting loans (Reuter, 1983; Stiglitz and Weiss, 1981). As 
creditors have imperfect foresight on debtor's repayment ability, they need financial power to absorb losses from defaulting debtors and to accept uneven repayments without going bankrupt (Baumol, 1952; Moeller and Sandberg, 2017). Dealers in this study described credit as a central element of network power mechanisms.

One female mid-level cannabis dealer (25) explained the price difference between credit and cash: "If I get it on credit, I pay 8,000 ( US\$ 960), and if I buy it, then I pay 7,000 ( US\$ 840) per hundred grams. And I'd sell it for 12,000 ( US\$ 1,440).” A male mid-level amphetamine and cannabis dealer (27) explained the situation as follows:

Since I had to get it on credit it, then I'm in no position to ask for a crazy price, and since he was the one who offered to lend it to me, then I have to take it for 130 kroner ( US\$ 16) a gram, right? That's not a problem; I can pass it on for 250 ( US\$ 30), so in any case, I double it, right, so I avoid screwing up.

Again, the dealer's reflections on prices are embedded in what can be described as a business narrative (which we return to later). The size of the credit risk premium is contingent on the history of the business relationship. A male mid-level amphetamine and cannabis dealer (27) explained this variation as follows:

When they buy it, they can get it for 35, 38 ( US\$ 4.2-4.6). If you're going to get it on credit, then you buy it at 40, 43, 45 ( US\$ 4.8-5.4). It depends on the quality, right? Who they are as well, right, and how often they come. 
Transactions in social networks are part of a long-term relationship and pricing reflects a mutual recognition of this. A female mid-level amphetamine dealer (46) explained the necessity of pricing drugs so both parties can earn money: "You have to make sure that people are able to make money on what you provide, at least if you are selling on credit. If it's not possible to earn money, then I won't get my money." Deciding on a credit price requires private information regarding the debtor's ability to repay, as well as recognition of the dual entitlement of both parties to earn money.

When asked if he could raise prices, a male mid-level amphetamine dealer (23) replied: "No, then you lose the customers, then it all goes to hell, right? The customers would get upset with you, the person above you would get upset with you, right?" The psychology of fairness stipulates that sellers cannot arbitrarily violate buyers' entitlement to the reference price. Buyers are hostile to unjustified price increases and fair behavior is instrumental in avoiding switching costs and realizing long-term profits.

As illustrated in the Norwegian cannabis market, this price stability also has other dimensions, as community standards stipulated that one gram cost 100 kroner ( US\$12). A male mid-level amphetamine dealer (36) said: "It's completely crazy! It's pretty much the same price as 20 years ago, right?” A male mid-level cannabis dealer (40) similarly commented:

Dealer: Prices on hash have gone up a lot. Buying hash these days is expensive as hell. We've become so picky about quality.

Interviewer: Because it had always cost 100 kroner ( US\$ 12)?

Dealer: It had always cost 100 kroner ( US\$ 12), a standard price. Then, it changed in 20062007, then, it changed. It started to cost a little more, and now when I got out in 2011, if you 
want a hecto, you had to put out 10,000 for the hecto ( US\$1,200). 100 kroner a gram ( US\$12). That was never the case before.

If illicit drug prices were only based on the standard of the drugs sold, a price increase for cannabis would be uncontroversial. Average potency has increased, while inflation has reduced the purchasing power of 100 kroner. However, community standards have exerted more power over cannabis prices in Norway than economic regularities.

Finally, power occurs in price competition at the wider market level. Economists have examined numerous ways in which firms in collusion can drive rivals out of the market by increasing their costs or reducing their competitiveness (Salop and Schefmann, 1983). Levitt and Venkatesh (2000) found that a gang lowered their prices below the profit breaking minimum to remain in control of a drug-selling area. There is only limited economic sociological research on power and prices, but Baker and Faulkner (1993) examined three price-fixing conspiracies where coalitions of organizations curtailed the competitive market by agreeing on prices. One female midlevel cocaine dealer (35) explained how she was part of such a conspiracy to counter a local price decrease:

A lot of Nigerians came to town, and they brought a lot of cocaine with them. So, there were a lot of meetings around that because that was supposed to prevent these Nigerians from bringing in cocaine. Because the quality of the products went up a lot and the price went down a lot. So, it became quite normal to regulate things, a part of doing business, right? 
This group of dealers cooperated to drive competitors out of the local market to keep prices stable and high. These competing drug distribution networks colluded and used economic power instead of resorting to physical violence, thereby saving on costs (Jacques and Wright, 2008). In these data it was striking how often such interventions were done without the use of violence.

\section{Status and reputation}

In the legal economy, firms invest in their reputation to produce trust and goodwill among customers while banks use credit ratings and other screening devices as indicators of status (Akerlof 1980; Stiglitz and Weiss, 1981; Uzzi, 1999). In the illegal drug economy, the ultimate status parameter is reputation (Anderson, 1999). The lack of information on partners and products implies that broad social categories can be associated with "morally hazardous" behavior (Reuter, 1983: 121; see also Jacques, Allen and Wright, 2014).

A male mid-level amphetamine dealer (27) commented on the status of low-level amphetamine dealers: "They use a lot of speed, and are really shattered, right, no teeth, no nothing." A male high-level amphetamine dealer (40) described how geographical distance was related to social distance and affected status and prices: "Because they came from out of town...it immediately went up in price.” A female mid-level amphetamine dealer (50) stated the following: "I never buy from foreigners. They hustle too much with the drugs," and a male high-level cannabis dealer (24) similarly commented: "I never sell to foreigners in Norway; it's a bunch of snitchers and idiots. Running around shooting in streets without hitting anything, right?” When asked about how one can discern the status of dealers, he explained the following:

You rely a lot on word of mouth; one does hear all kinds of things. You don't get a CV from selling drugs; you get a kind of word of mouth CV, but it's mostly about what you hear about people. 
A recurring theme in the interviews was how status and reputation were closely associated with the quality of drugs sold, but also on who were "good" people. Friendship narratives were often an integrated part of such talk, and there were sometimes a thin line between these and descriptions of who offered good prices to reasonable prices in a more economic mode of talk. A male high-level heroin dealer (41) explained: "If you offer good quality, then you'll have a lot of clients. That's just how it is." Conversely, low-quality drugs and overpricing often lead to conflicts. A male mid-level amphetamine dealer (36) stated: "So the ones that are stupid cheat too much because they are too greedy, and they come up with a bad product. And then people are pissed off, and then there's actually trouble right away. Like, why the fuck are you selling that shit for?" The aggressiveness and potential violence that is implicit here is closely connected to the fact that much drug dealing happen within the context of a violent street culture.

A female mid-level amphetamine dealer (23) explained how she rebuilt her reputation after inadvertently selling low-quality drugs at too high a price: "I had to spend quite a lot of time building my reputation. Getting my reputation back. So then, I went and gave free stuff to my regular customers as an apology." Unfair prices violate the established expectations of socially embedded economic relationships. Therefore, when this dealer inadvertently sold low-quality drugs, she compensated her buyers to apologize for the mistake with her original price. In doing this, she invested in her reputation of being a fair and "friendly" dealer. Status is important in all markets and, as the interviewees suggested, it is dynamic and easily lost. When pricing their products, dealers are also managing their status and considering the costs of potentially losing buyers.

\section{Embeddedness promotes trust}

Status was inextricably linked with trust and the interviewees stressed the importance of having reliable partners. The basic decision concerns how many collaborators to work with — the branching 
factor (Caulkins and Baker, 2010). A male mid-level amphetamine dealer (39) stated: "If you have too many people involved, then, sooner or later there'll be someone who'll squeal on you, so it's better to deal with as few people as possible."

Selection into the network is influenced by referrals and reputation for business acumen. However, the reliability of referrals and reputation is difficult to assess because there are no audited books to consult (Reuter, 1983). Hence, some dealers attempt to deduce information regarding their network partners by interpreting police actions. A male mid-level amphetamine dealer (24) explained:

If there are four, five people I'm selling to, been selling to for maybe a year, and I start selling to another one, and then I get the police at my door a few days later, in the next round I, like, skip out on him (laughs).

The prices paid reflect performance within the network, similar to a "tiered price structure" (Uzzi, 1999: 153) in which credit costs are reduced over time as the ability to repay is demonstrated. A male mid-level amphetamine dealer (46) stated that "those who had worked to deserve it" could access larger quantities of drugs. A male mid-level amphetamine and cannabis dealer (27) similarly commented:

You don't just meet them on the street. You must've known them for a while to get an idea about where the fuck they come from. Then, you try it out at the start, and then, you go over a kind of a threshold, right, and if they see you as a trustworthy guy, then it's okay. 
Social embeddedness develops as time progresses and grants access to larger quantities of drugs. We described in the institutional analysis how the information dealers derive from their interpersonal relations is used to manage their overall network. Getting rid of untrustworthy partners and rewarding reliable partners improves overall network performance and security. However, this logic can also entail expectations and pressure to expand the business' scope. A male mid-level amphetamine dealer (23) commented:

They tell you that the whole time you're picking up 200 grams, right? They say, can't you just take the kilo instead, right? Then, you don't have to come so often, so it's not just that; then, you see that oh, I can get it ten kroner ( US\$1.2) cheaper per gram, so I can make ten thousand more, right? (...) You never go back again and get less; that won't work because you also gotta, not just that, but you also tie yourself to the people you sell to; they expect being able to buy what they buy now.

Hence, dealers could be drawn into the business of distributing drugs and find it hard to stop. A male mid-level amphetamine dealer (46) stated:

Even though you know you're hot, you don't stop. You're just a bit more careful, but you don't stop. It's totally crazy, completely crazy, all logic suggests that you must stop, put it all away. No. Just a little bit. Just gonna do that one thing, and that thing, and that thing. “Just gonna.” If you're really big, then drugs will follow you forever.

Embeddedness has advantages and disadvantages. Uzzi and Lancaster (2004) found that corporate law firms gained a competitive advantage in pricing their products when their partners shared 
"private" information. Here, embeddedness improves decisions and increases expediency because dealers retain trusted partners and avoid the costs of finding new partners. However, the sense of obligation increases, which could lead to less rational risk assessments, as the interviewees explained. Ekland-Olson, Lieb and Zurcher (1984) also found that drug dealers tended to only socialize with offenders similar to themselves. The downside of trusting relationships was overembeddedness, in which loyalty became more important than risk management. Therefore, ultimately, the insularity and idiosyncrasy associated with maintaining embedded ties can become a liability.

In brief, the social embeddedness approach in economic sociology highlights how illegal drug transactions occur in networks where power, status, and trust influence pricing. Financial power affects prices through credit, stability, and competition with other dealers. Further, the seller's status, broad social categories, and more or less symbolic aspects derived from reputation also affect prices. Finally, interpersonal trust is pivotal in illegal transactions at higher distribution levels, as underlined by participants in this study, as well as in previous research (e.g. Benson and Decker, 2010; Decker and Chapman, 2008; Desroches, 2007; Morselli, 2009). Partners invest their time, effort, and money in developing and maintaining interpersonal relationships. These mechanisms help explain why and how criminal network structure changes over time and can persist in a hostile institutional environment.

\section{THE CULTURAL APPROACH TO PRICES}

According to Beckert (2011: 771), culture is part of price formation in four different ways: it produces technologies that make pricing more uniform; it can shape expectations for future market developments; it can influence which objects are legitimate; and it can tempt individual preferences. Arguably, culture goes even further because prices are framed in stories of fairness, reasonable costs, and acceptable losses (MacKenzie, Muniesa and Siu, 2007; Shiller, 2017). Common cultural 
understanding reduces uncertainty, price volatility, switching costs, and promotes trust. Below, we emphasize how three influential cultures affect prices in drug distribution.

\section{Business culture}

Dealers in this study alternated between different cultural rationales, transmitted through stories, when explaining pricing. The most prominent was a business narrative (Sandberg and Fleetwood, 2017, see also Dwyer and Moore, 2010) that reflected general market culture. The dealers presented themselves as serious businesspeople and narrated this role by using the economic terminology of supply and demand, customer preferences, risk assessments, expected profits and business strategies copied from the legal economy.

A male mid-level amphetamine dealer (46) stated: “There are times when it's the buyer's market and times when it's the seller's." Another male high-level cannabis dealer (24) explained how supply and demand influenced prices: “It's kind of like diamonds and gold; shouldn't be a lot of it, but there's a whole lot, so you have to hold back a little, so the prices don't get too low." Other dealers reflected on finding an optimal market schedule in which they could maximize earnings. The underlying rationale is a business logic of maximizing profit. A male mid-level cannabis dealer (44) stated "I earn more by selling it cheap than by selling it at a higher price. That way, you sell a lot more." While this might seem obvious, there are several other concerns that could be taken, for example selling out as soon as possible to avoid being caught with large amounts of drugs or selling to friends because that is safer or more convenient. With little legitimate information on the wider market situation, drug dealers depend on constant narrative interpretation of the limited available information. The ongoing cultural interpretation illustrates how even the economic logic is continuously performed in markets (MacKenzie, Muniesa and Siu, 2007).

Dealers used symbolic boundary work (Copes, Hochstetler and Williams, 2008) to distinguish between those who implemented business logic and those who did not. A male high- 
level heroin dealer (41) used business sensibilities to categorize his partners. He first explained that he began dealing heroin because of his own use and then gradually started dealing more:

Then, you start talking about money, a lot of money. I was able to get a million in cash and hundreds of grams or a kilo of heroin at a time. I've had very good contacts because in those circles, word gets out quickly as to who is trustworthy, who is solid and who's not, those you benefit from knowing. The ones that come with it, they're thinking money.

In accordance with the business narratives, "thinking money" is a good thing to this dealer. It is a sign of experienced professional actors who do not mix their business with other concerns. Pricing decisions are embedded in cultures and draw legitimacy from them, whether that is increasing prices because of high demand, lowering prices to attract more customers, or deciding who to work with. In this way, business culture is a 'tool kit' (Swidler, 1986) and sellers can promote certain narratives to justify controversial choices, such as declining discounts or introducing price increases. A male mid-level ecstasy dealer (29) explained how he would insist on a certain price and referenced the supply situation in the local market as a source of legitimacy, even when dealing with known customers:

I wouldn't go down in price no matter what. If a very good customer came to me and said, "Would it be possible to get this much for this little? I'm kind of running low on cash?" Sometimes I'd be with it, but for the most part, 150 ( US\$ 18) was the price no matter how much you'd buy. Since I was the only dealer, I didn't have any problems insisting on that. 
This dealer faced situations in which he had to justify the prices he was charging to his customers, but perhaps also to himself. When dealers insisted on higher prices even for known partners, they would refer to a general market culture as a way to frame and, thereby, depersonalize their choices to retain their status and trust. If this dealer was more deeply involved in a culture in which sellers and buyers were friends, this position would have been more controversial.

\section{Cultural narratives of friendship}

Pricing decisions depended on the interpretation of sellers and buyers' roles. Drug dealing in social networks is commonly associated with a friendship narrative of trust and reliability. Some dealers sell drugs cheaper to friends, even though these friendships mainly revolve around drug use and sales. A male high-level heroin dealer (41) mentioned times when he was dealing amphetamines and cocaine:

I bought around 100 grams, mostly for myself, and then I sold about half of it and took half myself, just because people would ask: "Do me a favor, just sell me a little bit." - "Ok, you can have some." Stuff like that. It's not like I bought it thinking that I was going to make money. It was more like I bought it because I thought, "that was some good coke," and then I gave out a little to people I knew.

This dealer emphasizes he was not in the business to make money and that selling was closely intertwined with using, which, again, was embedded in social networks. Another male mid-level cannabis dealer (27) explained how he would give his friends better prices: 
Dealer: It's more about having friends. I mean, in hash circles in any case, it's about, well, you have a maximum price, which is sixty kroner maybe ( US\$ 7.2), right, friends get it for 55 ( US\$ 6.6).

Interviewer: How much do they have to buy to get it at 55-60 then ( US\$ 6.6-7.2)? We're talking about?

Dealer: Well, then we're only talking about a five, five for three, right, that's a good buddy price. That's gotta be pretty good.

Social embeddedness can be integrated into narratives to such a degree that prices for friends can even have a separate name ("buddy-price"). In this case, the low price goes beyond instrumentalist calculations of establishing trustworthy economic relationships (Williamson, 1993). The rules of fairness have broad implications in the friendship narrative compared to the business narrative. Between friends, there are higher expectations for favors that return no economic gain. A female mid-level cannabis dealer (25) explained it in this way:

I did sell hash in the neighborhood where I lived, to my old friends who had trouble getting it (...) it was very very good hash, though. A very rare one. That's what I did (...) I was actually doing it as a favor for my friends.

While "buddy-prices" are most common at lower levels of the distribution chain, they can also be present at higher levels. A male high-level cannabis dealer (24) mentioned the following about a large drug deal: 
We're on a friendly basis with those who are there picking up and, right, so the prices get reduced quite a lot. We'd stay and live there for a month in the same house, together with them trying it out, and go out and party and relax.

Even at high levels, cannabis supply could be influenced by a particular market culture (Aspers, 2011) in which business narratives are frowned upon (Coomber, Moyle and South, 2016). The delineation between the business and friendship cultural narratives described above were not always clear however. Dealers frequently shifted between cultural logics, and trust and status for example, were valued in both business and friendship narratives. These cultural narratives can also be part of negotiations. Sellers can emphasize business culture and narratives of supply and demand to justify price increases, while buyers can appeal to cultural narratives of friendship to get lower prices.

\section{Street culture of violence and respect}

The most important culture in many drug markets is a violent street culture. This culture has been described as a "set of informal rules governing interpersonal public behaviour, particularly violence" (Anderson, 1999: 33; see also Jacobs, 2000) in an extensive literature on subcultures emerging from street life. Bourgois (2003: 9) described drug dealing as the material base of street culture and noted that it not only offers an alternative forum for personal dignity but also a lifestyle of violence, substance abuse, and internalized rage. Street capital (Sandberg, 2008) involves the practical rationality of street culture, including prescriptions on how to avoid the police and display readiness to use violence when disrespected. Most violence described by the interviewees was the result of unpaid debt (see also Moeller and Sandberg, 2017). A male mid-level cannabis dealer (49) said: 
A friend of mine got his finger cut off. They got it from here, up here, split his bone, tore it up and ripped out the whole thing. So he just got a hole now. So he walks like this now. He couldn't make up for himself. He had fronted drugs.

A low-level cannabis dealer (20) witnessed violence when partaking in debt collection:

Once I was joining someone who had a rumor for being sick in their heads. Was going to collect some money from a guy. They were fucking insane to him, cracking the fingers, cracking his ribs and cutting him with a knife.

Building a reputation for violence is an integral part of drug dealing in street culture, as, through violence, dealers gain respect and deter attacks (Jacques and Wright, 2008; Lauger, 2014; Mullins, 2006). Street capital influences pricing. A reputation for violence can increase partners' willingness to pay the asking price and limit negotiations, as disagreement can be seen as a sign of disrespect. Further, street culture promotes aggressive competition. Violent dealers increase competitors' costs and can drive less violent dealers from the market (Levitt and Venkatesh, 2000; Papachristos, 2009). In this way, street culture contributes to the high risk premium on illicit drugs.

However, in street culture, power and status can be more important than profits. A male mid-level amphetamine dealer (46) described how he tolerated costs associated with less proficient network partners in order to have a diverse and entertaining social circle:

You always have to keep useful idiots that think they're tricking you, and you know they're tricking you, but they're such useful idiots that you just keep them. The court has many facets, and some you keep for entertainment value and others for monetary value (laughs). 
It's totally crazy, it's an environment that's totally on the edge. You don't care if you get your money's worth because you gotta have some funny idiots too (laughs). Charming idiots that are just funny. You see the value in that.

In street culture, making money is highly valued and many drug dealers compare themselves to successful business executives. Still, as street culture builds on social networks where status is highly valued, this occasionally trumps rational business behavior. In such cases, social concerns, or attempts at building street capital by being generous and hedonistic, or to demonstrate superiority through humor (Gruner, 2000), can require high costs by lowering prices on drugs.

In essence, the cultural approach in economic sociology can be used to study how narratives shape prices and the way markets are constantly performed through such stories. The most significant difference in this study can be seen in the business and friendship cultures. General market culture is reflected in a business narrative that exists in all drug markets while the particular market culture reflects specific local marketplaces, social networks, and drug subcultures to a larger degree. Some of these can have a culture that emphasizes friendship while others are more influenced by a street culture concerned with respect and violent retaliation. While the cultural narratives of business culture tend to increase prices, friendship narratives reduce them. Regardless, many dealers used both interchangeably. This may reflect how street culture includes both an emphasis on making money, often using violent means, as well as how it is embedded in networks of friends and more hedonistic values. The result is mechanisms where known partners receive favorable prices while socially distant outsiders are taken advantage of.

\section{DISCUSSION}

Drug market scholars have recognized that price formation is not purely an economic endeavor. 
The surrounding legal context, the characteristics of the interpersonal relations, and the social distance between participants all exert influence on prices. However, these insights have rarely been connected theoretically, and despite their scale, scope and importance to criminology, illegal drug markets are still poorly understood (Bushway and Reuter, 2008). Drawing from a sample of qualitative interviews with imprisoned, mainly mid- and upper-level drug dealers in Norway, we explored pricing practices through the lens of three economic sociological traditions. Though they overlap, these traditions emphasize different aspects of the social context that surrounds price formation. We combined this with perspectives from economic theory on imperfect markets, criminological studies of drug markets, and cultural perspectives to better understand illicit drug pricing. The aim was to synthesize these diverging disciplinary contributions into a coherent theoretical framework under the umbrella of economic sociology.

The institutional economic sociological approach to drug distribution demonstrates how formal criminalization and law enforcement increases prices. The basic mechanisms consist of the risk of criminal sanctioning that entails pervasive uncertainty throughout the distribution process, which translates to added costs. These costs vary with offenders' perceptions of sanction severity and law enforcement intensity and, therefore, distribution level and region. Dealers seek niches with low sanctions and high profits and actively attempt to manipulate and divert police attention. Combined, this helps explain the variability in observed drug prices across times and places. When distributing drugs above the street level, no two transactions are priced the same (Gallet, 2014). Inadvertently, institutional rules may lead to lower prices because severe criminal sanctions make expediency a central concern. Drug distribution is a "batch process," where a shipment's arrival is not timed with an assessment of market demand and dealers seek to avoid inventory (Caulkins and Baker, 2010:220; see also Adler, 1993). The inventory problem also demonstrates how prices vary 
with timing and information, as the surrounding institutional context can be more or less hostile at different times (Baumol, 1952; Simon, 1978).

However, even lower prices do not necessarily improve expediency, as buyers may not have sufficient cash to pay up-front. Credit is a common way to alleviate this problem (Desroches, 2007; Moeller and Sandberg, 2015). The added risk premium is an advantage to sellers; however, there are costs associated with collecting the debt and defaults. Deciding on a credit price is complicated in the legal economy and even more precarious under illegality. Different prices will attract different debtors. In economic theory, this is an example of a principal-agent problem where a higher price entails adverse selection and "moral hazard" among borrowers. The financially most unreliable borrowers are the ones willing to pay high credit prices (Reuter, 1983:119-23; Stiglitz and Weiss, 1981). This is problematic in drug distribution, as potential debtors may be drug users who are unable to repay or maybe even unwilling to respect agreements, for example, if they have a high standing in street culture. The absence of formal institutions to protect creditors makes the process contingent on interpersonal trust or a reputation for willingness to use violence (Moeller and Sandberg, 2017). The economic sociological perspective on trust in interpersonal relationships aims at understanding them in terms of social networks.

Networks in this context are economic structures generated to reduce uncertainty (Uzzi and Lancaster, 2004; Williamson, 1981). However, criminal networks are not simply social networks operating in criminal contexts. Their covert setting requires a constant tradeoff between operational efficiency and protection from law enforcement (Benson and Decker, 2010; Decker and Chapman, 2008; Morselli, 2009). Interpersonal trust is more important than economic efficiency and this has implications for price formation. From an economic perspective, recurrent transactions with known partners involve investments in the relationship and, therefore, foregone gain in individual transactions. However, investment in buyer-seller relationships also entails low switching costs, 
repeat purchase discounts, and price stickiness. Stable prices for trusted partners further increase embeddedness and, therefore, the network's security. Conversely, buyers who have the power to negotiate prices may increase price variation. Negotiating power was contingent on the seller's social proximity, the history of the business relationship, and the timing of the transaction in relation to the dealers' inventory.

Status and trust were other important pricing mechanisms. In the absence of public product standards and warranties, status in the form of reputation becomes crucial for dealers. Reputation concerns both the product's quality, as well as the dealer's trustworthiness. In economic signaling theory, a product's quality is a standard criterion that determines a seller's status (Akerlof, 1980; Beckert, 2011). From a sociological perspective, Podolny (2005: 837) found only a "loose linkage between actual quality and perceptions of individual producers." The quality of illicit drugs is easily manipulated but hard to assess. Therefore, pricing that reflects the expected quality (see Caulkins, 2007) represents the dealer's honesty, integrity, and status. Dealers have an incentive to keep prices low for known partners because it will help their status and develop a trusting relationship. In the long-term, this will keep them in business and keep costs from law enforcement interventions down.

This study demonstrates how dealers use pricing as a means for strategic maneuvering. They adjust the tradeoff between efficiency and security by changing prices when institutional constraints change. Sometimes, lowering prices can increase embeddedness and trust in interpersonal relations. At other times, when security is not the primary concern of dealers they can increase prices to get more profit. This strategic management occurs under consideration of the network as a whole. Dealers also sometimes assess if parts of their network need strengthening, or other parts can be neglected or removed. Both behavioral economics and economic sociology stress the role of joint judgments in pricing processes. Dual entitlement, community standards, and fairness limit the scope of price variation (Kahneman, Knetsch and Thaler, 1979; Uzzi and 
Lancaster, 2004). Pricing is thus an intersubjective process and not only a question of limited information: "strategies of action do not exist independently from the situation but are formed in social interaction through the interpretation of the attitude of relevant others" (Beckert, 2003: 777).

Contemporary research on illegal networks focuses on quantitative analyses of topology, or the structure of network ties, leaving out the actual content (McGloin and Kirk, 2016). Our qualitative approach addresses what goes on in interpersonal ties by noting how dealers use pricing to collect information on reliability and trustworthiness. This focus on the dynamic interactions in dyadic ties can contribute when examining how networks develop over time. A cultural approach to pricing is necessary to better understand how participants interpret these processes and the social context in which they take place.

Several of the mechanisms we described in the sections on institutional context and social networks are interwoven with and produced by dealers' cultural environment and transmitted through storytelling. The question of how to maneuver in the illegal context, for example, depends on an interpretation of criminal sanction risk. Similarly, interpersonal relationships in networks require narration and cultural performance, even signaling through prices. Providing favorable prices is a performance of a trusted relationship and contributes to strengthening the relationship further. These cultural stories and interpretations vary substantially between markets for different types of drugs, as well as with the socio-economic context and dealers individual differences. The cultural variation is so immense and pivotal that cultural narratives and performances can be seen as making these markets (MacKenzie, Muniesa and Siu, 2007).

Institutional and social network mechanisms have a cultural dimension that is often seen in dominant cultural narratives within markets. Institutional context and social networks are made sense of, diffused, and communicated through stories. Combined they create a market culture that makes learning and relative stability possible. The most important cultural difference in drug 
markets we have identified can be captured by the distinction between business, friendship and street culture narratives. These narratives illustrate the cultural variety often found at different distribution levels and in markets for different types of drugs. High-end dealing of harder drugs for example, is often framed within a business narrative while social supply and dealing with softer drugs are framed within friendship narratives. Friendship narratives were also important for some high-level cannabis dealers.

Arguably, street culture most clearly affects drug distribution. This subculture emerges from social and economic marginalization, includes a high acceptance of illegal activity and drug use, and emphasizes violent retaliation when ones 'respect' is challenged (Bourgois 2003). Street culture is backed by a well-developed narrative repertoire that upholds and reproduces many illegal drug markets (Lauger 2014). As supported by insights from behavioral economics as well, these narratives embolden participants and devaluates the extralegal deterrent effects of stigma and shaming (Pogarsky, Roche, and Pickett, 2018). From a cultural economic sociological perspective, pricing decisions can thus be seen as the result of either one of the dominant cultural narratives in a market - or the outcome of an ongoing negotiation between actors using business-, friendship- and street cultural narratives as resources when making their case.

\section{CONCLUSION}

This paper offered a theoretical synthesis of traditions both within and outside criminology. Our aim was to introduce economic sociology to criminology, where it has received little attention. Following an interdisciplinary approach, we also demonstrated how an economic sociology of illegal markets can extend insights from behavioral economics and cultural studies, into a coherent criminology of illegal drug markets. This project is ambitious and covers much theoretical ground. It is an explorative endeavor that we hope will be followed by research focusing on the particular 
mechanisms we have identified, but also on other aspects of illegal drug markets. The perspectives we have introduced can be applied to co-offending behavior in markets for other illegal commodities as well.

Economic sociology has a long tradition of analyzing a multitude of economic phenomena in varying social contexts (Granovetter, 1985; Swedberg, 2003). Highlighting institutions, networks, and culture, economic sociologists have revealed how formal regulations, interpersonal ties, and cultural narratives shape economic relations and influence prices. Arguably, these elements are even more important for understanding illicit transactions. Economic researchers who have investigated drug prices find it difficult to explain variation across time, space, and distribution levels. The discrepancies underline the importance of including social contexts and actors' perceptions of networks and markets in the analysis. Variation in interpersonal relationships, and perceptions of these, also help explain why official data on drug prices vary with the source of those data.

In this study, we have highlighted how pricing decisions are affected by variations in the regulatory framework between drug types and regions, how dealers decide on prices under consideration of longer-term strategic thinking on their network as a whole, and how specific market cultures and narratives influence decisions. We believe that economic sociology can include all these contextual perspectives while still including a space for profit-seeking behavior and bounded rationality. As demonstrated in this explorative study, an analysis of illicit markets based on economic sociology can begin with identifying the institutional context, social networks, and culture within which these markets are embedded. Combined this can be a starting point for a theoretically coherent and empirically fruitful criminology of illegal drug markets. 


\section{REFERENCES}

Adler, Patricia, A. 1993. Wheeling and dealing: An ethnography of an upper-level drug dealing and smuggling community. Columbia University Press.

Anderson, Elijah. 1999. Code of the street: Decency, violence, and the moral life of the inner city. New York: W. W. Norton.

Aspers, Patrik. 2011. Markets. Cambridge: Polity Press.

Akerlof, George, A. 1980. A theory of social custom, of which unemployment may be one consequence. The Quarterly Journal of Economics 94:749-75.

\section{https://doi.org/10.2307/1885667}

Baker, Wayne, E., and Robert Faulkner, R. 1993. The social organization of conspiracy: Illegal networks in the heavy electrical equipment industry. American Sociological Review 58:837-60. Retrieved from http://www.jstor.org/stable/2095954

Baumol, William, J. 1952. The transactions demand for cash: An inventory theoretic approach. The Quarterly Journal of Economics 66:545-56. https://doi.org/10.2307/1882104

Becker, Gary. S. 1968. Crime and punishment: An economic approach. The Journal of Political Economy 76:169-217.

Becker, Gary, S., Kevin, M. Murphy, and Michael Grossman, M. 2006. The market for illegal goods: The case of drugs. Journal of Political Economy 114:38-60. https://doi:10.1086/498918

Beckert, Jens. 2003. Economic sociology and embeddedness: how shall we conceptualize economic action? Journal of economic issues 37:769-787.

https://doi.org/10.1080/00213624.2003.11506613 
Beckert, Jens. 2011. Where do prices come from? Sociological approaches to price formation. Socio-Economic Review 9:757-86. https://doi:10.1093/ser/mwr012

Beckert, Jens, and Frank Wehinger. 2013. In the shadow: Illegal markets and economic sociology. Socio-Economic Review 11:5-30. https://doi.org/10.1093/ser/mws020

Benson, Jana, S., and Scott Decker. 2010. The organizational structure of international drug smuggling. Journal of Criminal Justice 38:130-8. https://doi.org/10.1016/j.jcrimjus.2010.01.001

Bourdieu, Pierre. 1984. Distinction. A social critique of the judgment of taste. London: Routledge.

Bourgois, Phillipe. 2003. In search of respect: Selling crack in El Barrio. Cambridge University Press.

Bushway, Shawn, and Peter Reuter. 2008. Economists' contribution to the study of crime and the criminal justice system. Crime and Justice 37:389-451. https://doi.org/10.1086/524283

Carruthers, Bruce. G. 2013. From uncertainty toward risk: The case of credit ratings. SocioEconomic Review 11:525-51. https://doi.org/10.1093/ser/mws027

Caulkins, Jonathan, P. 2007. Price and purity analysis for illicit drugs: Data and conceptual issues. Drug and Alcohol Dependence 90:61-8. https://doi.org/10.1016/j.drugalcdep.2006.08.014

Caulkins, Jonathan, P., and David Baker. (2010). Cobweb dynamics and price dispersion in illicit drug markets. Socio-Economic Planning Sciences 44:220-30. https://doi.org/10.1016/j.seps.2010.06.001

Caulkins, Jonathan, P., and Peter Reuter. 2010. How drug enforcement affects drug prices. Crime and Justice 39:213-71. https://doi.org/10.1086/652386

Caulkins, Jonathan, P., and Peter Reuter. 2006. Illicit drug markets and economic irregularities. Socio-Economic Planning Sciences 40:1-14. https://doi.org/10.1016/j.seps.2004.08.002 
Caulkins, Jonathan, P., and Peter Reuter. 1996. The meaning and utility of drug prices. Addiction 91:1261-4. https://doi.org/10.1080/09652149639484

Coomber, Ross, Leah Moyle, and Nigel South. 2016. The normalisation of drug supply: The social supply of drugs as the "other side" of the history of normalisation. Drugs: Education, Prevention and Policy 23:255-63. https://doi.org/10.3109/09687637.2015.1110565

Copes, Heith, Scott Jacques, Andy Hochstetler, and Tim Dickinson. 2015. Interviewing offenders. In The Routledge handbook of qualitative criminology (Pp. 157-72), eds. Heith Copes and Mitchell Miller. London: Routledge.

Copes, Heith, Andy Hochstetler, and Patrick J. Williams. 2008. "We weren't like no regular dope fiends": Negotiating hustler and crackhead identities. Social Problems 55:254-70. https://doi.org/10.1525/sp.2008.55.2.254

Decker, Scott, H., and Margaret Chapman. 2008. Drug smugglers on drug smuggling. Philadelphia: Temple University Press.

Desroches, Frederick. 2007. Research on upper level drug trafficking: A review. Journal of Drug Issues 37:827-44. https://doi.org/10.1177/002204260703700405

Diamond, Peter, A. 1971. A model of price adjustment. Journal of Economic Theory 3:156-68. https://doi.org/10.1016/0022-0531(71)90013-5

Durkheim, Emile. 1933 [1893]. On the division of labor in society. Translated by George Simpson, fourth edition. New York: The Free Press.

Dwyer, Robyn, and David Moore. 2010. Beyond neoclassical economics: Social process, agency and the maintenance of order in an Australian illicit drug marketplace. International Journal of Drug Policy 21:390-8. https://doi.org/10.1016/j.drugpo.2010.03.001 
Ekland-Olson, Sheldon, John Lieb, and Louis Zurcher. 1984. The paradoxical impact of criminal sanctions: Some microstructural findings. Law \& Society Review 18:159-78. https://doi: $10.2307 / 3053401$

Fligstein, Neil, and Luke Dauter. 2007. The sociology of markets. Annual Review of Sociology 33:105-28. https://doi.org/10.1146/annurev.soc.33.040406.131736

Gallet, Craig A. 2014. Can price get the monkey off our back? A meta-analysis of illicit drug demand. Health economics 23:55-68. https://doi.org/10.1002/hec.2902

Golub, Andrew, Bruce Johnson, and Eloise Dunlap. 2005. Subcultural evolution and illicit drug use. Addiction Research \& Theory 13:217-29. https://doi.org/10.1080/16066350500053497 Granovetter, Mark. 2005. The impact of social structure on economic outcomes. The Journal of Economic Perspectives 19:33-50. Retrieved from http://www.jstor.org/stable/4134991

Granovetter, Mark. 1985. Economic action and social structure: The problem of embeddedness. American Journal of Sociology 91:481-510. https://doi.org/10.1086/228311

Granovetter, Mark, and Richard Swedberg. 1992. The sociology of economic life. Boulder: Westview Press.

Gruner, Charles R. 2000. The game of humor: A comprehensive theory of why we laugh. New Brunswick, NJ: Transaction Publishing House Publisher.

Jacobs, Bruce. A. 2000. Robbing drug dealers: Violence beyond the law. New York: Aldine de Gruyter.

Jacques, Scott, Andrea Allen, and Richard Wright. 2014. Drug dealer's rational choices on which customers to rip-off. International Journal of Drug Policy 25:251-6. https://doi.org/10.1016/j.drugpo.2013.11.010

Jacques, Scott, and Richard Wright. 2008. The relevance of peace to studies of drug market violence. Criminology 46:221-54. https://doi.org/10.1111/j.1745-9125.2008.00102.x 
Kahneman, Daniel, Jack Knetsch, and Richard Thaler. 1986. Fairness as a constraint on profit seeking: Entitlements in the market. American Economic Review 76:728-741. https://doi.org/10.2307/1806070

Klemperer, Paul. 1987. Markets with consumer switching costs. The Quarterly Journal of Economics 102:375-94. https://doi.org/10.2307/1885068

Krippner, Greta, R. 2002. The elusive market: Embeddedness and the paradigm of economic sociology. Theory and Society 30:775-810. https://doi.org/10.1023/A:1013330324198

Kvale, Steinar, and Svend Brinkmann. 2008. InterViews: Learning the craft of qualitative research interviewing. Sage.

Lauger, Timothy R. (2014). Violent stories, personal narratives, street socialization, and the negotiation of street culture among street-Oriented youth, Criminal Justice Review 39:182200. https://doi.org/10.1177/0734016814529966

Levitt, Steven, D., and Sudhir A. Venkatesh. 2000. An economic analysis of a drug-selling gang's finances. The Quarterly Journal of Economics 115:755-89. https://doi.org/10.1162/003355300554908

MacKenzie, Donald, Fabian, Muniesa, and Lucia Siu. (Eds.) (2007). Do economists make markets? On the performativity of economics. Princeton University Press.

Manski, Charles, F., John V. Pepper, and Carol, V. Petrie (Eds.). 2001. Informing America's policy on illegal drugs: What we don't know keeps hurting us. National Research Council: National Academy Press, Washington, D.C.

McGloin, Jean Marie, and David S. Kirk. 2010. Social network analysis. In Handbook of quantitative criminology (Pp. 209-24), eds. Alex R. Piquero and David Weisburd. New York: Springer. 
Moeller, Kim. 2018. Drug market criminology: Combining economic and criminological research on illicit drug markets. International Criminal Justice Review 28:191-205. https://doi.org/10.1177/1057567717746215

Moeller, Kim, and Sveinung Sandberg. 2017. Debts and threats: Managing inability to repay credits in illicit drug distribution. Justice Quarterly 34:272-96. https://doi.org/10.1080/07418825.2016.1162321

Moeller, Kim, and Sveinung Sandberg. 2015. Credit and trust: Management of network ties in illicit drug distribution. Journal of Research in Crime and Delinquency 52:691-716. https://doi.org/10.1177/0022427815583912

Morselli, Carlos. 2009. Inside criminal networks (Vol. 8). New York: Springer.

Morson, Gary, and Morton Schapiro. 2017. Cents and sensibility: What economics can learn from the humanities. Princeton University Press.

Mullins, Christopher W. 2006. Holding your square: Masculinities, streetlife and violence. Abingdon on Thames: Routledge.

Nooteboom, Bart. 1996. Trust, opportunism and governance: A process and control model. Organization Studies 17:985-1010. https://doi.org/10.1177/017084069601700605

Papachristos, Andrew V. 2009. Murder by structure: Dominance relations and the social structure of gang homicide. American Journal of Sociology 115:74-128. https://doi.org/10.1086/597791

Pearson, Geoffrey, and Dick Hobbs. 2003. Kingpin? A case study of a middle market drug broker. The Howard Journal of Criminal Justice 42:335-47. https://doi.org/10.1111/1468$\underline{2311.00290}$

Presser, Lois, and Sveinung Sandberg. (Eds) 2015. Narrative criminology: Understanding stories of crime. New York University Press. 
Podolny, Joel, M. 2005. Status signals: A sociological study of market competition. Princeton, NJ: Princeton University Press.

Pogarsky, Greg, Sean Patrick Roche, and Justin T. Pickett. 2018. Offender decision-making in criminology: Contributions from behavioral economics. Annual Review of Criminology 1:379-400. https://doi.org/10.1146/annurev-criminol-032317-092036

Reuter, Peter. 1983. Disorganized crime: The economics of the visible hand. Cambridge, M.A.: MIT press.

Reuter, Peter, and Jonathan P. Caulkins. 2004. Illegal "lemons": Price dispersion in cocaine and heroin markets. Bulletin on Narcotics 56:141-65.

Reuter, Peter, and Mark A. Kleiman. 1986. Risks and prices: An economic analysis of drug enforcement. Crime and Justice 7:289-340. https://doi.org/10.1086/449116

Salop, Steven, C., and David Scheffman, T. 1983. Raising Rivals' Costs. The American Economic Review 73:267-71. https://doi.org/10.1016/S0167-6245(98)00012-2

Sandberg, Sveinung. 2008. Black drug dealers in a white welfare state: Cannabis dealing and street capital in Norway. The British Journal of Criminology 48:604-19. https://doi.org/10.1093/bjc/azn041

Sandberg, Sveinung, and Jennifer Fleetwood. 2017. Street talk and Bourdieusian criminology: Bringing narrative to field theory. Criminology and Criminal Justice 17:365-81. https://doi.org/10.1177/1748895816672909

Shiller, Robert, J. 2017. Narrative economics. American Economic Review 107:967-1004. https:///doi-org/10.1257/aer.107.4.967

Simon, Herbert. 1979. Rational decision-making in business organizations. The American Economic Review 69:493-513. https://doi.org/10.2307/1808698 
Smith, Charles, W. 1989. The social construction of value. Berkeley, CA: University of California Press.

Stiglitz, Joseph E., and Andrew Weiss. 1981. Credit rationing in markets with imperfect information. The American Economic Review 71:393-410. Retrieved from http://www.jstor.org/stable/1802787

Streeck, Wolfgang, and Kathleen Thelen. 2005. Introduction. In Beyond Continuity: Institutional change in advanced political economies (Pp. 1-39), eds. Wolfgang Streeck \& Kathleen Thelen. Oxford University Press.

Swedberg, Richard. 2003. Principles of economic sociology. Princeton, NJ: Princeton University Press.

Swidler, Ann. 1986. Culture in action: Symbols and strategies. American Sociological Review 51:273-86. http://www.jstor.org/stable/2095521

Thompson, Grahame F. 2003. Between hierarchies and markets: The logic and limits of network organization. Oxford University Press.

Thornton, Sarah. 1995. Club cultures: Music, media, and subcultural capital. Cambridge: Polity Press.

Titman, Sheridan. 1985. Urban land prices under uncertainty. American Economic Review 75:50514. https://doi.org/10.2307/1814815

Uzzi, Brian. 1999. Embeddedness in the making of financial capital: How social relations and networks benefit firms seeking financing. American Sociological Review 64:481-505. Retrieved from http://www.jstor.org/stable/2657252

Uzzi, Brian, and Ryon Lancaster. 2004. Embeddedness and price formation in the corporate law market. American Sociological Review 69:319-44. https://doi.org/10.1177/000312240406900301 
Velthuis, Olav. 2005. Talking prices. Princeton University Press.

Weber, Max. 1978 [1922]. Economy and society: An outline of interpretive sociology. Berkeley: University of California Press.

Williamson, Oliver, E. 1993. Calculativeness, trust, and economic organization. The Journal of Law \& Economics 36:453-86. https://doi.org/10.1086/467284

Williamson, Oliver, E. 1981. The economics of organization: The transaction cost approach. American Journal of Sociology 87:548-77. https://doi.org/10.1086/227496

Wright, Richard, T., and Scott Decker. 1994. Burglars on the job. Boston, MA: Northeastern University Press.

Young, Jock. 1971. The drugtakers: The social meaning of drug use. London: MacGibbon \& Kee.

Zuckerman, Ezra, W. 1999. The categorical imperative: Securities analysts and the illegitimacy discount. American Journal of Sociology 104:1398-438. https://doi.org/10.1086/210178 